\title{
Plastic Deformation of Metal/Graphene Composites with Bimodal Grain Size Distribution: a Brief Review
}

\author{
A.G. Sheinerman ${ }^{1,2}$ \\ ${ }^{1}$ Institute of Problems of Mechanical Engineering, Russian Academy of Sciences, St. Petersburg 199178, Russia \\ ${ }^{2}$ Saint Petersburg State University, 7/9 Universitetskaya nab., St. Petersburg 199034, Russia
}

Received: December 10, 2020

\begin{abstract}
We briefly review the experimental data and analytical models that describe plastic deformation and fracture processes in metal/graphene composites with a bimodal grain size distribution of the metallic matrix. We demonstrate that such composites can have high strength combined with good ductility. The effects of dislocation plasticity, grain boundary sliding and fracture processes on the mechanical properties of such composites are discussed.
\end{abstract}

Owing to their excellent mechanical properties, last years heterogeneous nanostructures in metals and alloys have attracted much attention (see, e.g., review [1]). Such heterogeneous nanostructures comprise metals and alloys with a bimodal grain size distribution [2-10], gradient nanostructures [11-19], bulk metals and alloys with nanoscale twins [6,20-24], as well as metals containing nanograins dispersed inside coarse grains [25]. In particular, experiments [2-10,26] and simulations [26-31] of plastic deformation of metals and alloys with a bimodal grain size distribution demonstrated a unique combination of high strength with decent ductility. In such materials, the plastically hard nanocrystalline $(\mathrm{nc})$ or ultrafine-grained (ufg) regions are responsible for ultrahigh strength, while plastically soft coarse grains provide high enough strain hardening and resulting good ductility. In addition, experiments [20-23] and modeling [32] demonstrated that very high strength combined with good ductility can be achieved in austenitic steels using the conjunction of a bimodal grain size distribution and the formation of growth twins in the coarse grains.

In parallel with the use of single-phase inhomogeneous metals and alloys, recently, significant progress has been made in the synthesis of metallic materials reinforced by graphene platelets (see [33-37] and references therein) or graphene nanoribbons [38] with high strength and good ductility. The simultaneous enhancement of strength and ductility in graphene-reinforced composites was attributed [37] to the trapping of dislocations by graphene platelets during plastic deformation, which enhances strain hardening and thereby improves both strength and ductility.

The combination of structural inhomogeneity in metals with addition of graphene platelets was first realized by Xiang et al. [39], who produced special bimodal $\mathrm{Mg} /$ graphene composites with laminated structures. In such composites, graphene-depleted layers consisting of coarse grains alternated with the layers comprising ultrafine grains and the majority of graphene platelets. The addition of graphene in the composites provided a dramatic increase in the yield strength and flow stress, although at the expense of reduced ductility. At the same time, due to the large distance between graphene platelets in the ufg matrix and the low volume fraction of graphene in coarse grains, plastic deformation in these composites was likely to occur in graphene-free regions, while the strengthening effect of graphene was mainly

Corresponding author: A.G. Sheinerman, email: asheinerman@gmail.com 

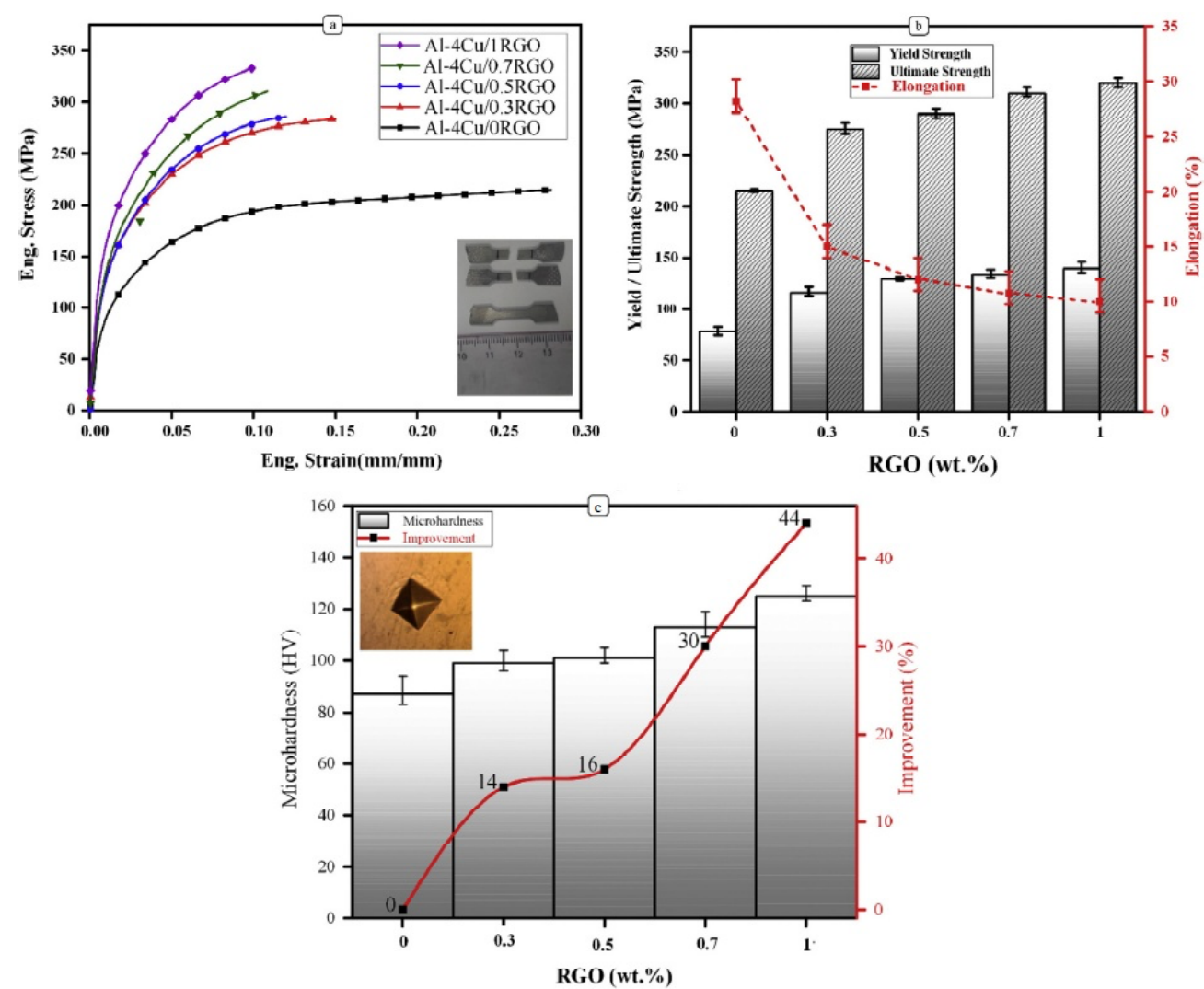

Fig. 1. (a) Engineering stress-strain curves for $\mathrm{Al}-4 \mathrm{Cu} / \mathrm{XRGO}$ nanocomposites for different $\mathrm{X}$ values. (b) Dependences of the yield strength, ultimate strength and elongation to failure of the $\mathrm{Al}-4 \mathrm{Cu} / \mathrm{XRGO}$ nanocomposites on $\mathrm{RGO}$ content. (c) An increase in the microhardness of $\mathrm{Al}-4 \mathrm{Cu} / \mathrm{RGO}$ nanocomposite as a function of the RGO content. Reproduced with permission from [41]. Copyright 2020, Elsevier.

related to grain refinement. However, the results of other studies on metal/graphene composites [33-37] and bimodal metallic materials [2-10] demonstrate that at certain conditions, combination of bimodal grain size distribution with graphene fillers can provide simultaneously high strength and good ductility of the composite.

In particular, Kurapova et al. [40] and KhoshghadamPireyousefan et al. [41] produced metal/graphene composites with the $\mathrm{Ni}$ [40] and $\mathrm{Al}-4 \mathrm{Cu}$ [41] matrices characterized by bimodal grain size distributions. The Al4Cu/graphene composites have shown an improvement of $79 \%, 49 \%$ and $44 \%$ of yield strength, ultimate strength, and Vickers hardness, respectively, for the nanocomposite containing $1 \mathrm{wt}$.\% of graphene in comparison to the unreinforced $\mathrm{Al}-4 \mathrm{Cu}$ alloy (Fig. 1). The high strength and hardness of the composite was accompanied by relatively good tensile ductility (characterized by uniform elongation of 10 percent).

The improvement in the yield and ultimate strength due to graphene addition is accompanied by a change in the failure character from purely ductile failure characteristic of graphene-free Al-4Cu to mixed (ductile and brittle) or purely brittle fracture. This can be seen in Fig.
2, which shows the fracture surfaces of $\mathrm{Al}-4 \mathrm{Cu}$ alloy and the $\mathrm{Al}-4 \mathrm{Cu} / 1 \mathrm{RGO}$ nanocomposite (containing 1 wt.\% rGO). In this figure, the fracture surface of the Al$4 \mathrm{Cu}$ alloy is covered with a large number of fine dimples (Figs. 2a and 2b), which points to the failure via the generation and convergence if voids. In contrast, the fracture surface of the $\mathrm{Al}-4 \mathrm{Cu} / 1 \mathrm{RGO}$ nanocomposite (Figs. 2c-2e) that has a lamellar structure (Figs. 2d and $2 \mathrm{e})$ demonstrates the existence of very fine cracks. Also, the presence of pulled out graphene has been observed [41] on the fracture surface of $\mathrm{Al}-\mathrm{Cu} / 1 \mathrm{RGO}$ nanocomposite. This implies that microcracks formed during tensile testing of this composite can decrease its ductility. The above result is in contrast to the observations [40] of fracture surfaces of bimodal Ni/graphene composites, which show the presence of voids. The reason can lie in the initial porosity of bimodal $\mathrm{Ni}$ / graphene composites fabricated in [40], in contrast to nearly fully dense $\mathrm{Cu}-4 \mathrm{Al}$ specimens produced in [41]. The formation of cracks in bimodal $\mathrm{Al}-4 \mathrm{Cu} / \mathrm{Gr}$ composites can be related to the formation of the bimodal grain structure, which is absent in graphene-free $\mathrm{Cu}-4 \mathrm{Al}$ alloy. As a result, the stress concentration due to the accumulation of dislocations at the boundaries between 


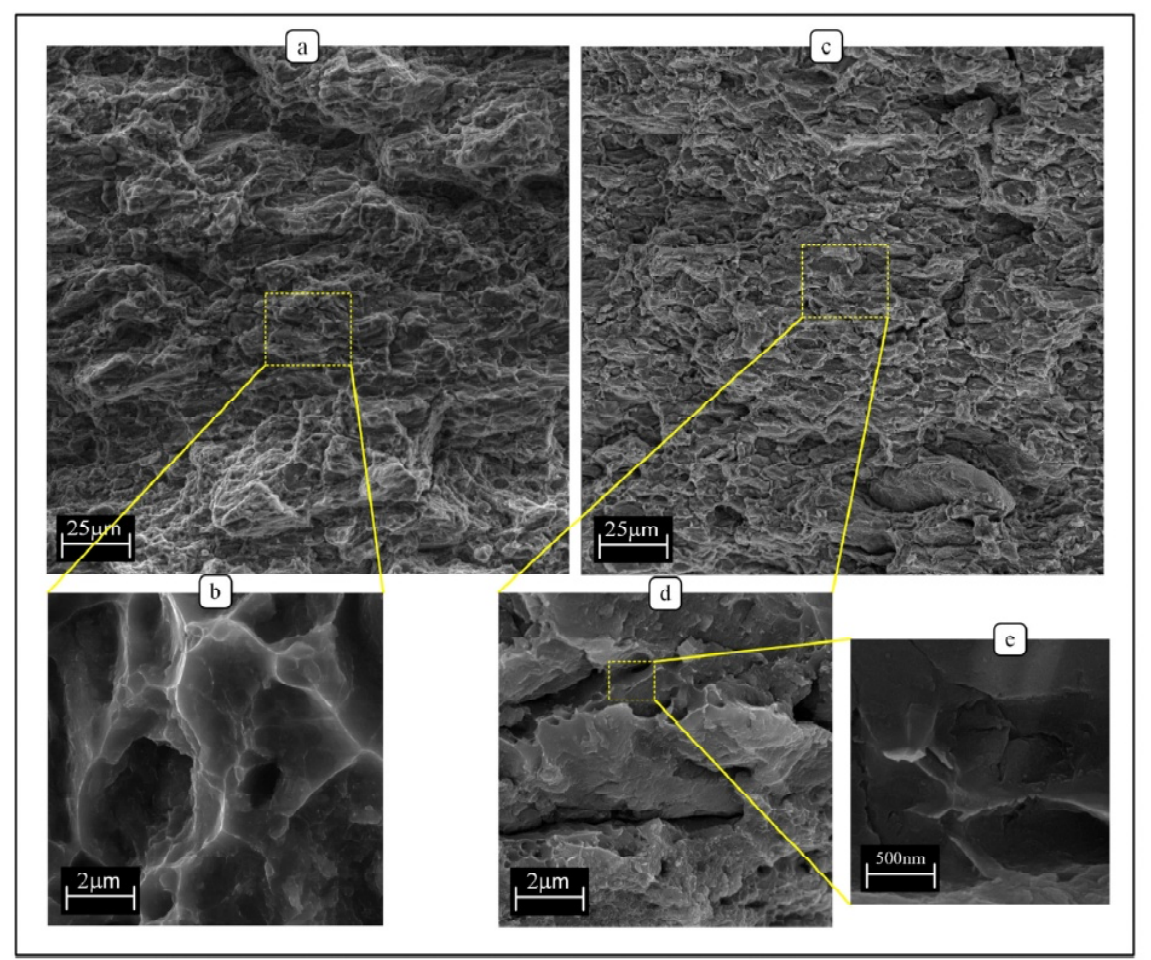

Fig. 2. The fracture surface of (a, b) $\mathrm{Al}-4 \mathrm{Cu}$ alloy and (c, d, e) Al-4Cu/1RGO nanocomposite. Reproduced with permission from [41]. Copyright 2020, Elsevier.

large and small grains can induce cracking over these boundaries, thereby reducing the ductility of the composites.

At the same time, the results of ref. [41] demonstrate that metal/graphene composites with a bimodal metallic matrix can provide a combination of high strength with reasonable ductility. This effect has been explained within mechanistic modeling [42]. Within model [42], a metal/ graphene composite is considered where the metallic matrix consists of large grains surrounded by a (nc)/ufg phase (Fig. 3). The stress for dislocation motion in the nc/ufg phase is supposed to be much higher than that in large grains, in accord with the Hall-Petch relation. Within model [42], dislocation pileups form in large grains at Frank-Read sources under the action of the applied uniform tensile load. These dislocation pileups create stress concentration, which enables dislocations to transmit from one large grain to another across the nc/ ufg phase, thereby providing macroscopic plastic flow in the solid. In addition, graphene platelets that are located either inside grains or at GBs provide additional strengthening and strain hardening due to the load transfer from the metallic matrix to graphene platelets, Orowan looping (for intragrain graphene platelets), obstruction of graphene platelets to dislocation emission from grain boundaries (GBs) (for GB graphene platelets), as well as dislocation back stresses due to dislocation accumulation near graphene platelets during plastic flow.
Within such an approach, the authors of ref. [42] calculated the stress-strain curves, yield strength and uniform elongation of pure $\mathrm{Cu}$ with a bimodal grain size distribution and compared them with the available experimental results [43]. Next, they considered the effect of intragrain and GB graphene platelets on the flow stress by considering various strengthening and strain hardening mechanisms. The resulting calculated engineering stress-strain curves for bimodal $\mathrm{Cu}$-graphene composites are shown in Fig. 4. These curves demonstrate that in the absence of cracking or void growth, bimodal $\mathrm{Cu} /$ graphene composites can have simultaneously high strength and high ductility. Both these parameters increase with the volume fraction of graphene as long as its concentration is not high enough to induce significant graphene agglomeration (leading to high porosity and the related degradation of mechanical properties).

The stress-strain curves allow one to calculate the critical uniform elongation, defined as the maximum tensile strain at which the specimen is stable with respect to necking. The critical uniform elongation $\varepsilon_{c}$ can be calculated using the Considère criterion [44] $\left.\left(\partial \sigma_{f} / \partial \varepsilon\right)\right|_{\varepsilon=\varepsilon_{c}}=\sigma_{f}$, where $\sigma_{f}$ and $\varepsilon$ are the true flow stress and true strain, respectively. The dependences of the critical uniform elongation $\varepsilon_{\gamma}$ for bimodal $\mathrm{Cu}$ with graphene platelets on its yield strength $\sigma_{\gamma}$ are plotted in Fig. 5. For comparison, Fig. 5 also displays such dependences for two similar specimens without graphene, one with the same grain size of the nc/ufg 


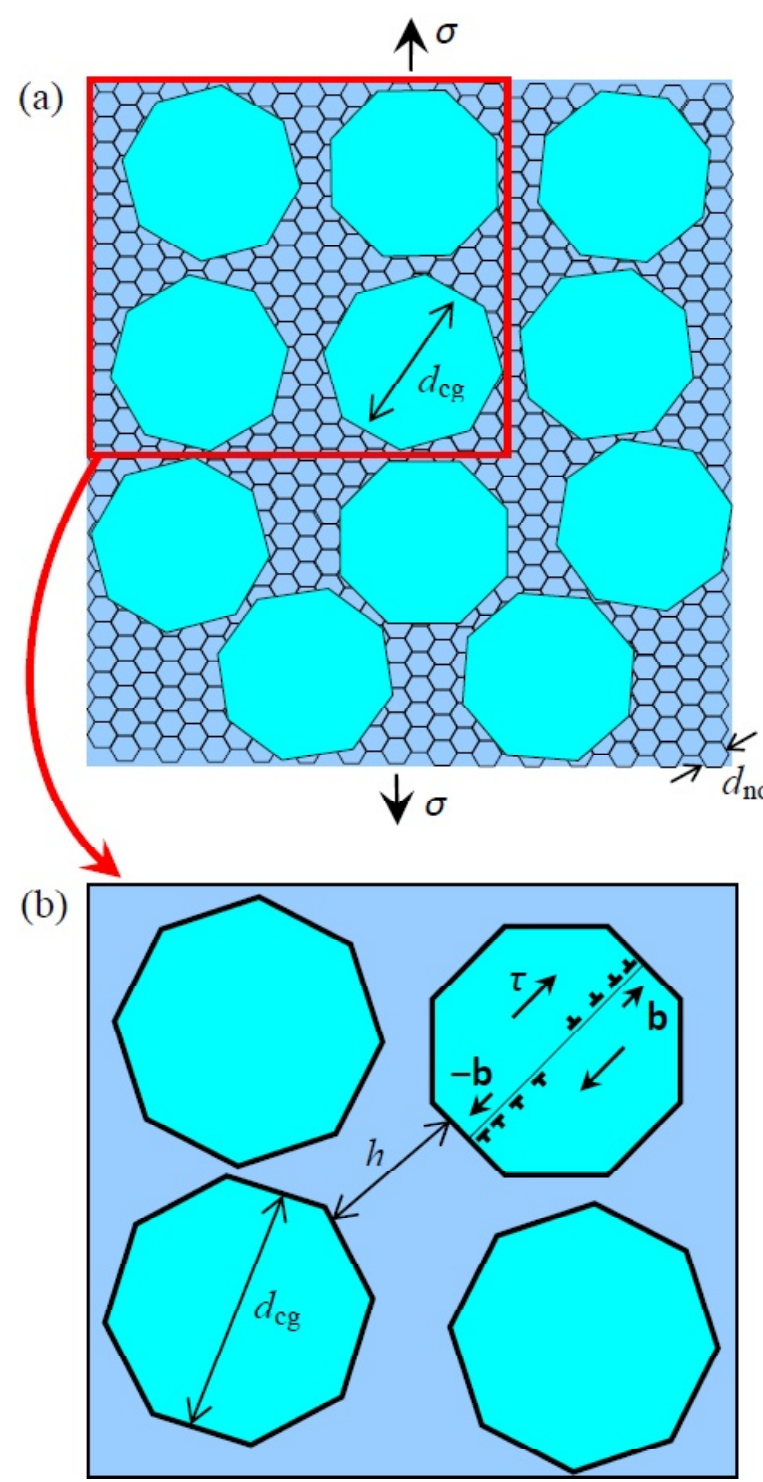

Fig. 3. Plastic deformation in a bimodal metal/graphene composite. (a) Bimodal metal/graphene composite under uniform tension. (b) Magnified fragment highlights a double dislocation pile-up in a large grain. Graphene platelets (lying either at GBs or inside large grains) are not shown in the figure. Adapted from [42].

phase $\left(d_{n c}=200\right.$ or $\left.300 \mathrm{~nm}\right)$, and the other with a smaller value of $d_{n c}\left(d_{n c}=75\right.$ or $\left.90 \mathrm{~nm}\right)$. Fig. 5 also shows that, for a given value of the volume fraction of the nc/ufg phase, graphene platelets can increase the yield strength and dramatically enhance the uniform elongation.

Thus, Fig. 5 predicts a combination of very high strength and excellent stability with respect to necking for bimodal metal/graphene composites. The comparison of Figs. 5a and 5b shows that if the specimen fails due to necking, then the best combination of strength and ductility can be expected for very small graphene platelets, whose length is smaller than the size of GBs in the ufg phase of the bimodal metallic matrix.
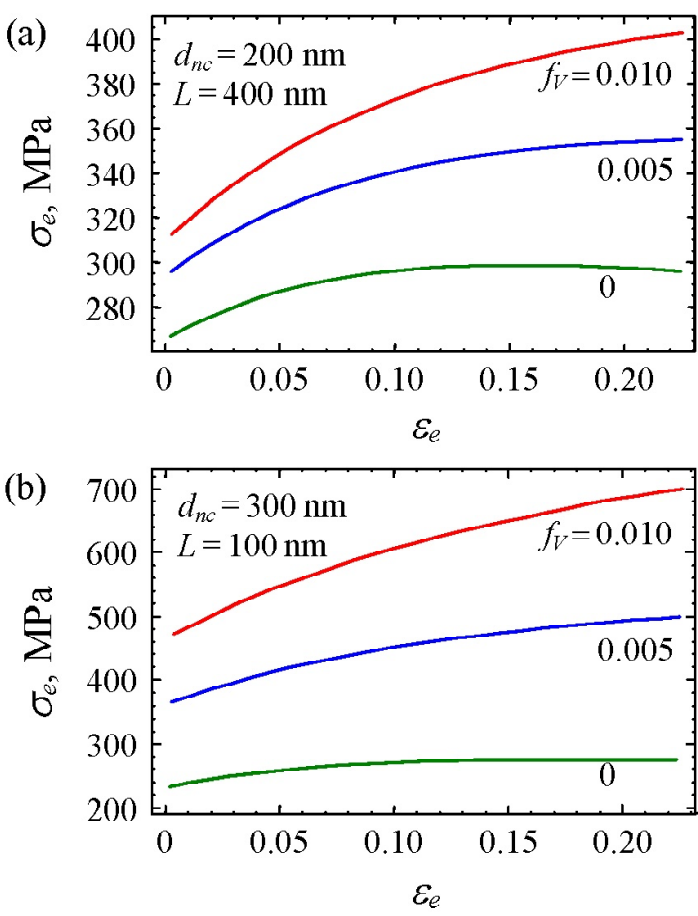

Fig. 4. Dependences of the engineering flow stress $\sigma_{e}$ of bimodal $\mathrm{Cu} /$ graphene composites on engineering strain $\varepsilon_{e}$, for the case of large (a) and small (b) graphene platelets (compared to the GB length in the nc/ufg phase). $d_{n c}, L$ and $f_{v}$ denote the grain size of the nc/ufg phase, the length of graphene platelets and the volume fraction of graphene, respectively. Adapted from [42].
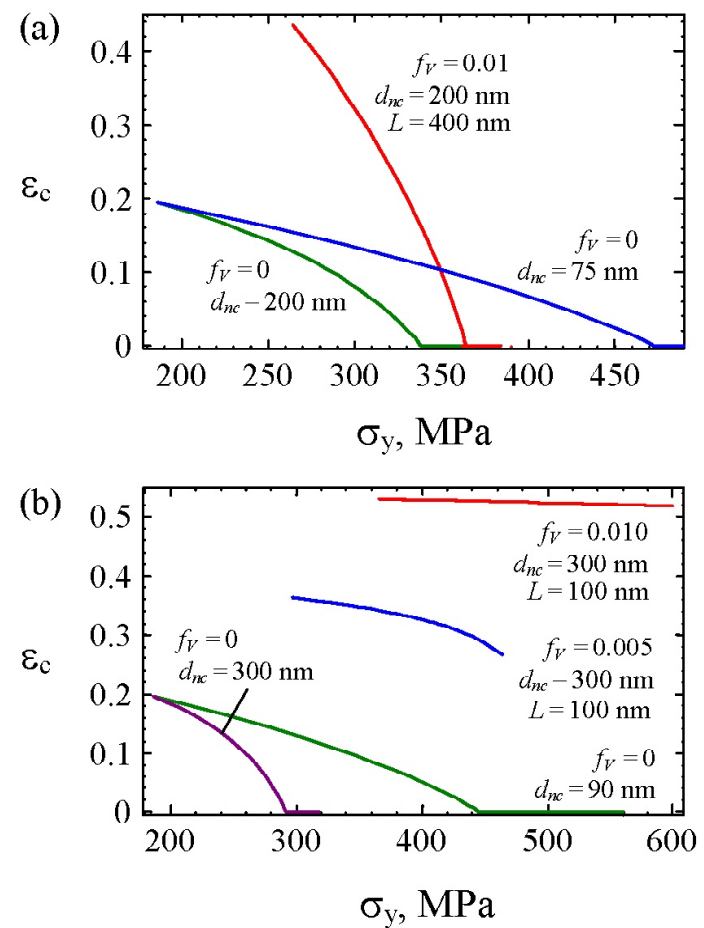

Fig. 5. Dependences of the critical uniform elongation $\varepsilon_{c}$ of bimodal $\mathrm{Cu} /$ graphene composites on their yield strength $\sigma_{y}$, for the case of large (a) and small (b) graphene platelets. $d_{n c}, L$ and $f_{v}$ denote the grain size of the nc/ufg phase, the length of graphene platelets and the volume fraction of graphene, respectively. Adapted from [42]. 


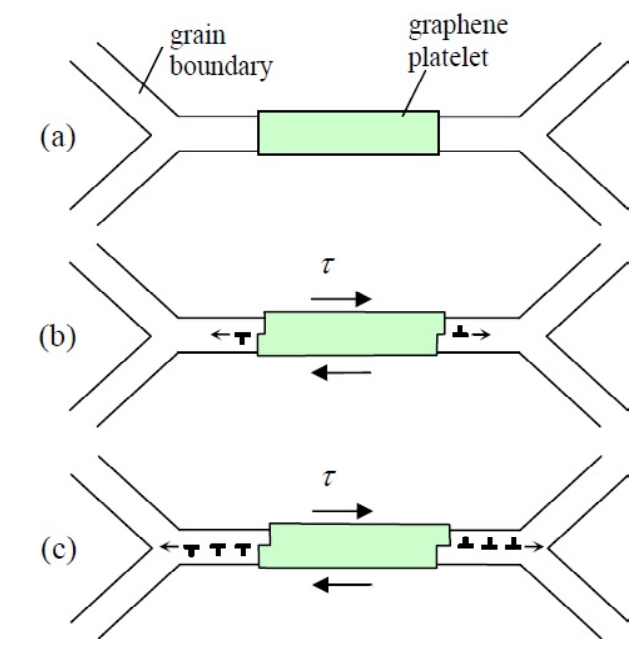

Fig. 6. GB sliding initiated by a graphene platelet at a GB. (a) GB containing a graphene platelet. Initial state. (b) Due to sliding of graphene monolayers or the graphene platelet as a whole under the action of the resolved shear stress $\tau$, dipoles of edge GB dislocations are generated at the edges of the platelet. The nucleating dislocations glide to the nearest triple junctions. (c) The process of dislocation nucleation and glide repeats many times. Adapted from [47].

The model proposed in ref. [42] takes into account only the action of dislocation plasticity. At the same time, GB sliding is often observed in metal-graphene composites. For example, in ref. [45], GB sliding was identified as the dominant deformation mechanism in a composite based on the AZ61 magnesium alloy with the addition of graphene platelets. In this study, the grain size of the alloy after the addition of graphene was around $4 \mu \mathrm{m}$. The reason for the activation of GB sliding in such a coarse-grained material is apparently associated with the relatively low shear strength of graphene in the direction parallel to the atomic layers, as well as, in some cases, with poor adhesion between graphene and the matrix. This is confirmed by computer simulations of the shear strength of graphite [45] and the simulations of the strength of interfaces between graphene and various materials (see, e.g., [46]). For example, the critical shear stresses for slip between graphene monolayers based on the results of ref. [45] can be estimated as $140 \mathrm{MPa}$. With a sufficiently small grain size of the nc/ufg phase, these stresses can in some cases be below the critical stress for the activation of intragranular plastic deformation. Consequently, in this situation, sliding along GBs containing graphene platelets becomes more favorable than the usual dislocation plasticity.

To account for the possibility of GB sliding, the authors of ref. [47] proposed a model that takes into account the combined effect of dislocation plasticity and
GB sliding on the yield strength of metal/graphene composites with a bimodal grain size distribution. Within this model, dislocation plasticity is realized, as in ref. [42], by the nucleation of dislocation pileups in large grains and their subsequent transmission to neighboring large grains across the nc/ufg phase. When considering GB sliding, the model assumes that, as a result of sliding of the monolayers of graphene platelets, dipoles of noncrystallographic edge dislocations with arbitrarily small Burgers vectors (equal in magnitude to the jump of displacements of sliding graphene monolayers) are formed at the edges of the platelets (Fig. 6). The nucleating dislocations glide to the nearest triple junctions (Fig. 6) or to the nearest dislocations of opposite sign, which are formed due to sliding along neighboring graphene platelets located in the same GB. The glide of GB dislocations results in GB sliding. The process of dislocation nucleation and glide repeats many times (Figs. $6 \mathrm{~b}$ and $6 \mathrm{c}$ ). The high stresses created by dislocations in triple junctions are partially removed due to the emission of some dislocations from triple junctions to the grain interiors and delocalization of triple junction dislocations, that is, their diffusion creep along GBs.

Within such a model, the authors of [47] calculated the yield strength of the bimodal Ni/graphene composite where plastic deformation occurs via the combined action of dislocation plasticity and GB sliding. The dependences of the yield strength $\sigma_{y}$ of the bimodal $\mathrm{Ni} /$ graphene composite on the graphene volume fraction $f_{v}$ are presented in Fig. 7, for two different grain sizes of the ufg phase, $d_{n c}=300 \mathrm{~nm}$ and $500 \mathrm{~nm}$. Also in this figure, for comparison, the dashed lines show similar dependences for the same composite without an account for GB sliding. From Fig. 7 it is clearly seen that an account for GB sliding leads to a rather strong decrease in the yield strength. Moreover, an increase in the graphene volume fraction above a certain value begins to lower the yield strength. This behavior is quite typi-

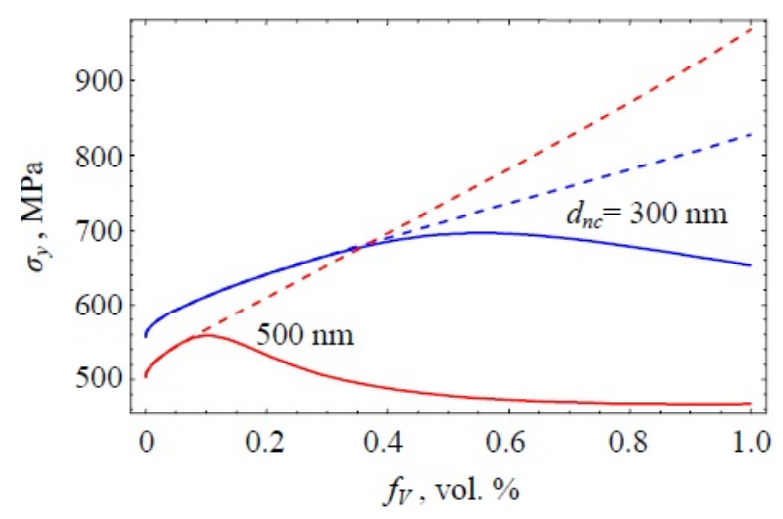

Fig. 7. Dependences of the yield strength $\sigma_{y}$ of the bimodal Ni/graphene composite on the graphene volume fraction $f_{v}$. Adapted from ref. [47]. 
cal for composites reinforced with graphene, where an increase in the graphene content can lead to the agglomeration of graphene platelets and the formation of voids around such agglomerates. However, in the case under consideration, a decrease in the yield strength with an increase in the graphene concentration is associated not with the formation of voids but with the activation of GB sliding.

Thus, the results of ref. [47] indicate that in bimodal metal/graphene composites with a high flow stress of the ufg phase of the metal matrix, GB sliding can reduce the yield strength, thereby reducing the hardness of the composites. A decrease in the yield strength of composites, associated with GB sliding, manifests itself when the volume fraction of graphene exceeds a critical value.

In summary, from the above brief review it follows that bimodal metal/graphene composites can possess a combination of high yield strength and reasonable strain to failure. The combination of bimodal grain size distribution and graphene platelets can result in high strain hardening of the composites, which favors both high strength and high ductility. At the same time, strain to failure of such composites can be reduced due to the brittle fracture, which can be related to the cracking at boundaries between large and small grains. At high flow stresses strength of the composites can also be limited due to the sliding over graphene platelets. Therefore, strength and ductility of such composites is determined by the interplay of various plastic deformation and fracture processes. Further analysis is needed to reveal the optimum structure of such composites that would provide the best combination of high strength and good ductility.

\section{ACKNOWLEDGEMENTS}

The author acknowledges the support of the Russian Foundation for Basic Research (grant 18-29-19086).

\section{REFERENCES}

[1] E. Ma and T. Zhu, Towards strength-ductility synergy through the design of heterogeneous nanostructures in metals, Mater. Today, 2017, vol. 20, no. 6, pp. 323-331. https://doi.org/10.1016/ j.mattod.2017.02.003

[2] V.L. Tellkamp, A. Melmed and E.J. Lavernia, Mechanical behavior and microstructure of a thermally stable bulk nanostructured Al alloy, Metall. Mater. Trans. A, 2001, vol. 32, pp. 2335-2343. https://doi.org/10.1007/s11661-0010207-6

[3] Y.M. Wang, M.W. Chen, F.H. Zhou and E. Ma, High tensile ductility in a nanostructured metal,
Nature, 2002, vol. 419, no. 6910, pp. 912-915. https:/ /doi.org/10.1038/nature01133

[4] C.C. Koch, Optimization of strength and ductility in nanocrystalline and ultrafine grained metals, Scripta Mater., 2003, vol. 49, vol. 7, pp. 657-662. https://doi.org/10.1016/s1359-6462(03)00394-4

[5] D. Witkin, Z. Lee, R. Rodriguez, S. Nutt and E. Lavernia, Al-Mg alloy engineered with bimodal grain size for high strength and increased ductility, Scripta Mater., 2003, vol. 49, no. 4, pp. 297-302. https://doi.org/10.1016/s13596462(03)00283-5

[6] Y.S. Li, Y. Zhang, N.R. Tao and K. Lu, Effect of thermal annealing on mechanical properties of a nanostructured copper prepared by means of dynamic plastic deformation, Scr. Mater., 2008, vol. 59, no. 4, pp. 475-478. https://doi.org/10.1016/ j.scriptamat.2008.04.043

[7] Y.H. Zhao, T. Topping, J.F. Bingert, J.J. Thornton, A.M. Dangelewicz, Y. Li, W. Liu, Y. Zhu, Y. Zhou and E.J. Lavernia, High tensile ductility and strength in bulk nanostructured nickel, Adv. Mater., 2008, vol. 20, no. 16, pp. 3028-3033. https://doi.org/10.1002/adma.200800214

[8] G. Dirras, J. Gubicza, Q.H. Bui and T. Szilagyi, Microstructure and mechanical characteristics of bulk polycrystalline Ni consolidated from blends of powders with different particle size, Mater. Sci. Eng. A, 2010, vol. 527, no. 4-5, pp. 1206-1214. https://doi.org/10.1016/j.msea.2009.09.050

[9] K.S. Raju, V.S. Sarma, A. Kauffmann, Z. Hegedus, J. Gubicza, M. Peterlechner, J. Freudenberger and G. Wilde, High strength and ductile ultrafinegrained Cu-Ag alloy through bimodal grain size, dislocation density and solute distribution, Acta Mater., 2013, vol. 61, no. 1, pp. 228-238. https://doi.org/10.1016/j.actamat.2012.09.053

[10] M.J. Shen, B.H. Zhang, X.J. Wang, M.F. Zhang, M.Y. Zheng and K. Wu, Significantly improved strength and ductility in bimodal-size grained microstructural magnesium matrix composites reinforced by bimodal sized SiCp over traditional magnesium matrix composites, Comp. Sci. Tech., 2015, vol. 118, pp. 85-93. https://doi.org/10.1016/j.compscitech.2015.08.009

[11] T.H. Fang, W.L. Li, N.R. Tao and K. Lu, Revealing extraordinary intrinsic tensile plasticity in gradient nano-grained copper, Science, 2011, vol. 331, no. 6024, pp. 1587-1590. https://doi.org/ 10.1126/science. 1200177

[12] A.Y. Chen, H.H. Ruan, J. Wang, H.L. Chan, Q. Wang, Q. Li and J. Lu, The influence of strain rate on the microstructure transition of 304 stainless steel, Acta Mater., 2011, vol. 59, no. 9, 
pp. 3697-3709. https://doi.org/10.1016/ j.actamat.2011.03.005

[13] H.T. Wang, N.R. Tao and K. Lu, Architectured surface layer with a gradient nanotwinned structure in a Fe-Mn austenitic steel, Scripta Mater., 2013, vol. 68, no. 1, pp. 22-27. https:// doi.org/10.1016/j.scriptamat.2012.05.041

[14] Y.J. Wei, Y.Q. Li, L.C. Zhu, Y. Liu, X.Q. Lei, G. Wang, Y.X. Wu, Z.L. Mi, J.B. Liu, H.T. Wang and H.J. Gao, Evading the strength-ductility trade-off dilemma in steel through gradient hierarchical nanotwins, Nature Commun., 2014, vol. 5, no. 1, art. 3580. https://doi.org/10.1038/ ncomms 4580

[15] X.L. Wu, P. Jiang, L. Chen, F.P. Yuan and Y.T. Zhu, Extraordinary strain hardening by gradient structure, Proc. Nat. Acad. Sci. USA, 2014, vol. 111, no. 20, pp. 7197-7201. https://doi.org/10.1073/ pnas. 1324069111

[16] X.L. Wu, M.X. Yang, F.P. Yuan, L. Chen and Y.T. Zhu, Combining gradient structure and TRIP effect to produce austenite stainless steel with high strength and ductility, Acta Mater., 2016, vol. 112, pp. 337-346. https://doi.org/10.1016/ j.actamat.2016.04.045

[17] Z. Ma, J. Liu, G. Wang, H. Wang, Y. Wei and H. Gao, Strength gradient enhances fatigue resistance of steels, Sci. Rep., 2016, vol. 6, no. 1, art. 22156. https://doi.org/10.1038/srep22156

[18] S.C. Cao, J. Liu, L.L. Zhu, L. Li, M. Dao, J. Lu and R.O. Ritchie, Nature-inspired hierarchical steels, Sci. Rep., 2018, vol. 8, art. 5088. https://doi.org/ 10.1038/s41598-018-23358-7

[19] L. Zhu, C. Wen, C. Gao, X. Guo, Z. Chen and J. Lu, Static and dynamic mechanical behaviors of gradient-nanotwinned stainless steel with a composite structure: Experiments and modeling, Int. J. Plasticity, 2019, vol. 114, pp. 272-288. https://doi.org/10.1016/j.ijplas.2018.11.005

[20] K. Lu, F.K. Yan, H.T. Wang and N.R. Tao, Strengthening austenitic steels by using nanotwinned austenitic grains, Scr. Mater., 2012, vol. 66, no. 11, pp. 878-883. https://doi.org/ 10.1016/j.scriptamat.2011.12.044

[21] H.T. Wang, N.R. Tao and K. Lu, Strengthening an austenitic Fe-Mn steel using nanotwinned austenitic grains, Acta Mater., 2012, vol. 60, no. 9, pp. 4027-4040. https://doi.org/10.1016/ j.actamat.2012.03.035

[22] F.K. Yan, G.Z. Liu, N.R. Tao and K. Lu, Strength and ductility of $316 \mathrm{~L}$ austenitic stainless steel strengthened by nano-scale twin bundles, Acta Mater., 2012, vol. 60, no. 3, pp. 1059-1071. https://doi.org/10.1016/j.actamat.2011.11.009
[23] F.K. Yan, N.R. Tao, F. Archie, I. Gutierrez-Urrutia, D. Raabe and K. Lu, Deformation mechanisms in an austenitic single-phase duplex microstructured steel with nanotwinned grains, Acta Mater., 2014, vol. 81, pp. 487-500. https://doi.org/10.1016/j.actamat.2014.08.054

[24] J.G. Kim, N.A. Enikeev, J.B. Seol, M.M. Abramova, M.V. Karavaeva, R.Z. Valiev, C.G. Park and H.S. Kim, Superior strength and multiple strengthening mechanisms in nanocrystalline TWIP steel, Sci. Rep., 2018, vol. 8, no. 1, art. 11200. https://doi.org/10.1038/s41598-01829632-y

[25] X. Wu, F. Yang, M. Yang, P. Jiang, X. Zhang, L. Chen, Y. Wei and E. Ma, Nanodomained nickel unite nanocrystal strength with coarse-grain ductility, Sci. Rep., 2015, vol. 5, no. 1, art. 11728. https://doi.org/10.1038/srep11728

[26] S. Ramtani, G. Dirras and H.Q. Bui, A bimodal bulk ultra-fine-grained nickel: Experimental and micromechanical investigations, Mech. Mater., 2010, vol. 42, no. 5, pp. 522-536. https://doi.org/10.1016/j.mechmat.2010.02.001

[27] L.L. Zhu and J. Lu, Modelling the plastic deformation of nanostructured metals with bimodal grain size distribution, Int. J. Plast., 2012, vol. 30-31, pp. 166-184. https://doi.org/ 10.1016/j.ijplas.2011.10.003

[28] L.L. Zhu, S.Q. Shi, K. Lu and J. Lu, A statistical model for predicting the mechanical properties of nanostructured metals with bimodal grain size distribution, Acta Mater., 2012, vol. 60, no. 16, pp. 5762-5772. https://doi.org/10.1016/ j.actamat.2012.06.059

[29] X. Guo, X.Y. Dai, G.J. Weng, L.L. Zhu and J. Lu, Numerical investigation of fracture behavior of nanostructured $\mathrm{Cu}$ with bimodal grain size distribution, Acta Mech., 2014, vol. 225, no. 4-5, pp. 1093-1106. https://doi.org/10.1007/s00707-0131050-8

[30] X. Guo, R. Ji, G.J. Weng, L.L. Zhu and J. Lu, Micromechanical simulation of fracture behavior of bimodal nanostructured metals, Mater. Sci. Eng. A, 2014, vol. 618, pp. 479-489. https://doi.org/10.1016/j.msea.2014.09.036

[31] A.C. Magee and L. Ladani, Representation of a microstructure with bimodal grain size distribution through crystal plasticity and cohesive interface modeling, Mech. Mater., 2015, vol. 82, pp. 1-12. https://doi.org/10.1016/ j.mechmat.2014.12.002

[32] L. Zhu, X. Guo, H. Ruan and J. Lu, Prediction of mechanical properties in bimodal nanotwinned metals with a composite structure, Comp. Sci. 
Technol., 2016, vol. 123, pp. 222-231.

https://doi.org/10.1016/j.compscitech.2015.12.013

[33] T. Borkar, H. Mohseni, J. Hwang, T.W. Scharf, J.S.

Tiley, S.H. Hong and R. Banerjee, Excellent strength-ductility combination in nickelgraphite nanoplatelet (GNP/Ni) nanocomposites, J. Alloys and Compds., 2015, vol. 646, pp. 135-144. https://doi.org/10.1016/ j.jallcom.2015.06.013

[34] M. Rashad, F. Pan, A. Tang, Y. Lu, M. Asif, S. Hussain, J. She, J. Gou and J. Mao, Effect of graphene nanoplatelets (GNPs) addition on strength and ductility of magnesium-titanium alloys, J. Magnesium Alloys, 2013, vol. 1, no. 3, pp. 242-248. https://doi.org/10.1016/ j.jma.2013.09.004

[35] X. Zhang, C. Shi, E. Liu, F. He, L. Ma, Q. Li, J. Li, W. Bacsa, N. Zhao and C. He, Achieving high strength and high ductility in metal matrix composites reinforced with a discontinuous three-dimensional graphene-like network, Nanoscale, 2017, vol. 9, no. 33, pp. 11929-11938. https://doi.org/10.1039/c6nr07335b

[36] Y. Jiang, R. Xu, Z. Tan, G. Ji, G. Fan, Z. Li, D.-B. Xiong, Q. Guo, Z. Li and D. Zhang, Interfaceinduced strain hardening of graphene nanosheet/aluminum composites, Carbon, 2019, vol. 146, pp. 17-27. https://doi.org/10.1016/ j.carbon.2019.01.094

[37] X. Liu, J. Li, E. Liu, C. He, C. Shi and N. Zhao, Towards strength-ductility synergy with favorable strengthening effect through the formation of a quasi-continuous graphene nanosheets coated Ni structure in aluminum matrix composite, Mater. Sci. Eng. A, 2019, vol. 748, pp. 52-58. https://doi.org/10.1016/ j.msea.2019.01.046

[38] M. Yang, L. Weng, H. Zhu, T. Fan, D. Zhang and H. Zhu, Simultaneously enhancing the strength, ductility and conductivity of copper matrix composites with graphene nanoribbons, Carbon, 2017, vol. 118, pp. 250-260. https://doi.org/ 10.1016/j.carbon.2017.03.055

[39] S. Xiang, X. Wang, M. Gupta, K. Wu, X. Hu and M. Zheng, Graphene nanoplatelets induced heterogeneous bimodal structural magnesium matrix composites with enhanced mechanical properties, Sci. Rep., 2016, vol. 6, no. 1, art. 38824. https://doi.org/10.1038/srep38824

[40] O.Y. Kurapova, I.V. Lomakin, S.N. Sergeev, E.N. Solovyeva, A.P. Zhilyaev, I.Y. Archakov and V.G. Konakov, Fabrication of nickel-graphene composites with superior hardness, J. Alloy. Compd., 2020, vol. 835, art. 155463. https://doi.org/10.1016/j.jallcom.2020.155463

[41] M. Khoshghadam-Pireyousefan, R. Rahmanifard, L. Orovcik, P. Švec, and V. Klemm, Application of a novel method for fabrication of graphene reinforced aluminum matrix nanocomposites: Synthesis, microstructure, and mechanical properties, Mater. Sci. Eng. A, 2020, vol. 772, art. 138820. https://doi.org/10.1016/ j.msea.2019.138820

[42] A.G. Sheinerman and M.Yu. Gutkin, Model of enhanced strength and ductility of metal/ graphene composites with bimodal grain size distribution, Metall. Mater. Trans. A, 2020, vol. 51, pp. 189-199. https://doi.org/10.1007/s11661019-05500-w

[43] Y.S. Li, Y. Zhang, N.R. Tao and K. Lu, Effect of thermal annealing on mechanical properties of a nanostructured copper prepared by means of dynamic plastic deformation, Scr. Mater., 2008, vol. 59, pp. 475-478. https://doi.org/10.1016/ j.scriptamat.2008.04.043

[44] A. Considčre, Mémoire sur l'emploi du fer et de l'acier dans les constructions, Annales des Ponts et Chaussées, 1885, vol. 9, pp. 574-775.

[45] Z. Liu, S. Zhang, J. Yang, J.Z. Liu, Y. Yang and Q. Zheng, Interlayer shear strength of single crystalline graphite, Acta Mech. Sin., 2012, vol. 28, no. 4, pp. 978-982. https://doi.org/10.1007/ s10409-012-0137-0

[46] S.J. Chen, C.Y. Li, Q. Wang and W.H. Duan, Reinforcing mechanism of graphene at atomic level: Friction, crack surface adhesion and $2 D$ geometry, Carbon, 2017, vol. 114, pp. 557-565. https://doi.org/10.1016/j.carbon.2016.12.034

[47] S.V. Bobylev, M.Yu. Gutkin and A.G. Scheinerman, Yield strength of metal-graphene composites with a homogeneous and bimodal grain structure, Mech. Sol., 2020, vol. 55, no. 1, pp. 22-31. https://doi.org/10.3103/s0025654420010069 